\title{
Letramentos digitais na formação de professores de inglês
}

\author{
Marcus de Souza Araújo \\ Faculdade de Letras Estrangeiras Modernas (FALEM) \\ Universidade Federal do Pará (UFPA) - Belém, PA - Brasil \\ marcusaraujocinterconect.com.br
}

\begin{abstract}
This paper aimed at investigating the promotion of eighteen student-teachers' digital literacy in a curricular subject of an English-language teaching undergraduate program. As for the methods, this research is considered a case study. The research instruments used were: three questionnaires, an interview, reflective reports, a selfassessment report, and the researcher's field notes. The research data were gathered in a curricular subject on technologies in an English-language teaching undergraduate program plays a relevant role in English-language teaching undergraduate programs, since it promoted the participants' digital literacy through the critical e reflexive familiarization of the participants with diverse digital technological interfaces for educational purposes, which were unknown to them at the beginning of the subject.
\end{abstract}

Resumo. Este artigo tem por objetivo investigar o fomento de práticas de letramentos digitais de dezoito alunos-professores a partir de uma disciplina curricular acadêmica do curso de Letras-Inglês. Com relação à metodologia, esta pesquisa se caracteriza como um estudo de caso e utiliza como instrumentos de pesquisa três questionários, uma entrevista, relatos reflexivos, autoavaliação e notas de campo do pesquisador. Os resultados apontam que uma disciplina curricular acadêmica específica sobre tecnologias tem papel relevante no curso de Letras-Inglês, pois promoveu o letramento digital dos participantes por meio da familiarização crítica e reflexiva de diversas interfaces tecnológicas digitais para propósitos educacionais, que eram desconhecidas por eles no início da disciplina.

\section{Introdução}

Letramentos digitais são processos dinâmicos que podem levar o sujeito a obter o conhecimento para o desenvolvimento de competências em ambientes digitais para a prática letrada de comunicação digital.

Complementando essa visão, Savage e Barnet (2015) discutem que o foco do letramento digital está nas práticas sociais, pois se devem considerar os aspectos sóciohistóricos das tecnologias digitais. Ressalte-se que as tecnologias vão se aperfeiçoando, mudando ao longo do tempo e determinado os interesses dos sujeitos. Além disso, segundo ainda esses autores, a importância e a necessidade de práticas pedagógicas de letramentos digitais na formação de professores se tornam mais que fundamentais a fim de que o professor possa conhecer, se familiarizar e se apropriar, crítica e reflexivamente, das ferramentas digitais. Dessa forma, Savage e Barnet (2015) salientam que o professor apresentará letramentos digitais para implementar 
VII Congresso Brasileiro de Informática na Educação (CBIE 2018)

Anais do XXIV Workshop de Informática na Escola (WIE 2018)

conscientemente ações didáticas com e por meio das tecnologias.

Minha concepção não está no uso dogmático das tecnologias, pois concordo com Kenski (2013, p. 96), ao afirmar que o uso das tecnologias (digitais) "em sala de aula não é sinônimo de inovação nem de mudança nas práticas tradicionais de ensino." Em outras palavras, as tecnologias, em si mesmas, não garantem mudanças pedagógicas potenciais no ensino-aprendizagem. A mudança efetuar-se-á no uso consciente e crítico que o professor fizer das tecnologias em seu contexto de sala de aula, adaptando-as para os interesses locais e regionais de seus alunos. Vejo, assim, as tecnologias como ferramentas que podem integrar, pedagogicamente, as práticas do professor e tornar a aprendizagem do aluno motivadora. Em outras palavras, concordo com Santiago, Nascimento e Sampaio (2016, p. 804) ao salientarem que "os recursos tecnológicos são suportes que devem ser utilizados com a finalidade de enriquecer as práticas educativas". Nessa direção, a escola e a universidade tornam-se um ambiente participativo, desafiador e integrador para os aprendizes da era digital, com seus diferentes ritmos e níveis de aprendizagem.

É mister ressaltar que Santos (2013) realizou um levantamento bibliográfico de dissertações e teses, no site da CAPES, apresentando um panorama sobre TDIC e formação de professores de língua inglesa, entre os anos 2000 e 2009. Complementando essa pesquisa, Araújo (2017) também organizou um levantamento bibliográfico no mesmo site no período de 2010 até o primeiro semestre de 2017. Os resultados de ambas as pesquisa refletem uma lacuna em estudos sobre a formação inicial de professores de inglês com o uso das TDIC no contexto brasileiro na área de Linguística Aplicada, foco das pesquisas.

Assim sendo, o objetivo deste trabalho é apresentar os resultados finais de uma pesquisa que investigou as práticas pedagógicas de um grupo de alunos do Curso de Letras-Inglês de uma Universidade Federal do norte do país para o fomento de letramentos digitais, a partir de uma disciplina curricular acadêmica específica para o uso das tecnologias digitais.

\section{Métodos}

Esta pesquisa se caracteriza como um estudo de caso (STAKE, 1995) por entendê-lo como uma abordagem qualitativa de natureza empírica, que busca compreender um caso contemporâneo a partir de um ambiente ou um contexto da vida real. Caminhando nessa direção, Stake (1995) afirma que o aspecto mais importante a ser considerado em um estudo de caso é a produção do conhecimento derivado do caso.

Esta pesquisa foi realizada durante a disciplina Tecnologias no ensino/aprendizagem de línguas estrangeiras. É mister ressaltar que essa disciplina foi incluída pela primeira vez no novo projeto político-pedagógico da Faculdade de Letras Estrangeiras Modernas (FALEM) em janeiro de 2010, com carga horária de $68 \mathrm{~h} / \mathrm{a}$. Em relação aos participantes, foram dezoito alunos, na faixa etária entre 23 e 27 anos, do turno noturno do Curso de Letras-Inglês da FALEM de uma Universidade Federal do norte do país.

Os instrumentos utilizados para esta pesquisa, para triangulação dos dados, foram três questionários, uma entrevista, relatos reflexivos, autoavaliação e notas de campo. Portanto, analisei e interpretei os conteúdos de cada resposta fornecida por cada participante a partir dos instrumentos de geração dos dados, na busca dos sentidos explícitos ou ocultos, apoiado em meu referencial teórico. Para Bardin (2011), esse é o 
VII Congresso Brasileiro de Informática na Educação (CBIE 2018)

Anais do XXIV Workshop de Informática na Escola (WIE 2018)

momento das interpretações inferenciais, da análise reflexiva, para o tratamento gerado pelos resultados dos dados.

\section{Resultados e discussão dos dados}

Os alunos-professores desta pesquisa reconhecem que ser usuário frequente de tecnologias no dia a dia não os torna habilitados a integrá-las no contexto escolar para fins pedagógicos. Por essa razão, a relevância de cursar uma disciplina no curso de Letras, especificamente, para saber usar de maneira reflexiva e integrada as tecnologias digitais no processo de ensino-aprendizagem de inglês, como pode ser visto no excerto a seguir:

\section{Transcrição 1: autoavaliação}

Gostei muito da disciplina de tecnologia porque pude entender como posso usar e integrar as tecnologias no meu contexto de sala de aula para ensinar inglês. Eu já uso o computador com muita frequência para várias coisas estudar, bater papo com meus amigos no Face(book), baixar música para ouvir, etc. - e também, é claro, uso muito o celular diariamente. Mas a disciplina me fez entender que mesmo sendo usuária das tecnologias digitais no meu dia a dia não é suficiente para eu ensinar inglês de maneira competente, integrando as tecnologias na minha sala de aula. (Participante A).

Por sua vez, o quadro-resumo 1, a seguir, mostra as recorrências dos alunosprofessores desta pesquisa em relação à contribuição da disciplina curricular específica de tecnologias do curso de Letras-Inglês para a fomentação do letramento digital desses participantes.

Quadro 1. Fomento do letramento digital

\begin{tabular}{|l|}
\multicolumn{1}{|c|}{ FOMENTO DO LETRAMENTO DIGITAL: } \\
DISCIPLINA CURRICULAR DO CURSO DE LETRAS-INGLÊS \\
\hline Ser usuário de tecnologias não habilita o aluno a ensinar inglês. \\
Ter segurança para pesquisar as potencialidades de uso de outras ferramentas \\
tecnológicas. \\
Usar as tecnologias de maneira crítica, reflexiva e pedagogicamente no ensino de inglês. \\
Aprender a analisar jogos educacionais digitais (JED), ferramentas tecnológicas e sites \\
para ensinar inglês.
\end{tabular}

Fonte: elaborado pelo autor.

O Quadro 1 reflete a importância de inclusão de uma disciplina curricular sobre tecnologias no curso de Letras-Inglês, levando o aluno a tornar-se letrado digitalmente para o uso pedagógico dessas tecnologias. As falas dos alunos-professores desta pesquisa mostram uma realidade, possivelmente comum no contexto brasileiro, ou seja, as pessoas (a maioria) estão em contato com as tecnologias com frequência no cotidiano. Vejamos outro excerto que ilustra essa constatação:

\section{Transcrição 2: autoavaliação}

Fiquei muito satisfeito em cursar uma disciplina bem específica sobre o uso das tecnologias no ensino de inglês no curso de Letras. Isso será muito importante para a minha formação porque a gente acha que sabe tudo de tecnologia. Eu uso muito o computador, a Internet, o celular diariamente, 
VII Congresso Brasileiro de Informática na Educação (CBIE 2018)

Anais do XXIV Workshop de Informática na Escola (WIE 2018)

com facilidade, mas descobrir que não sei ensinar inglês com essas ferramentas. (Participante B).

Nessa direção, fica evidente na transcrição 2 que o participante B é um usuário competente de tecnologia, ou seja, domina algumas ferramentas tecnológicas no dia a dia. O que me leva a constatar que esse participante é letrado digitalmente, mas o seu letramento está relacionado apenas ao uso próprio. Não obstante, ao pensar nas tecnologias voltadas para o ensino de inglês, o participante $\mathrm{B}$ admite não possuir esse tipo de letramento digital, o que em sua fala seria "descobrir que não sei ensinar inglês com essas ferramentas". Ressalte-se que "essas ferramentas" as quais esse informante faz referência em sua fala são o computador, a Internet e o telefone celular.

Outro exemplo é mostrado a seguir ao apontar a necessidade de uma formação formal para o professor para o uso pedagógico das tecnologias no ensino de inglês. $\mathrm{O}$ excerto a seguir elucida essa concepção:

\section{Transcrição 3: relato reflexivo}

Reconheço a necessidade de instruir o professor a saber usar melhor as tecnologias para um determinado propósito pedagógico para ensinar inglês, porque, no geral, o professor não sabe isso. Assim, o professor pode adaptar a tecnologia com atividades de inglês centradas nos alunos, de acordo com suas necessidades. Sem essa instrução um pouco mais formal o professor pode ficar inseguro e a tecnologia ser considerada, apenas, um suporte na aula de inglês. (Participante C).

Por suas declarações, posso inferir que o participante $\mathrm{C}$ percebe a importância de uma formação mais acadêmica, por meio de uma disciplina específica de tecnologia inserida no curso de graduação ou de um curso de formação continuada ou por meio da transversalidade das tecnologias no currículo, para o professor de inglês saber usar de maneira pedagógica as tecnologias em sala de aula. Ainda segundo sua percepção, a maioria dos professores não detém conhecimento suficiente para usar as tecnologias no contexto escolar por não possuir essa formação.

Assim sendo, a disciplina curricular sobre tecnologias mostrou aos alunosprofessores possibilidades de uso das TDIC por meio de práticas pedagógicas e de integração funcional ao ensino de inglês, com a articulação entre teoria e prática. O que posso entender, dessa forma, é que a disciplina se tornou um elo de mediação de uso reflexivo, eficiente e pedagógico para os futuros professores de inglês, tornando-os, então, sujeitos letrados digitalmente para fins pedagógicos.

\section{Conclusões}

Este estudo de caso teve como foco principal investigar o uso pedagógico das tecnologias digitais na formação inicial de professores de inglês da Faculdade de Letras Estrangeiras Modernas de uma Universidade Federal do norte do país. O foco está na prática pedagógica, para o processo de ensino-aprendizagem e para as práticas de letramentos digitais. $\mathrm{O}$ meu lócus para a realização desta pesquisa se justifica na medida em que acredito na necessidade da formação reflexiva de professores pré-serviço de inglês para atuarem de maneira confiante e motivadora nos contextos escolares da Educação Básica brasileira, na tentativa de transformarem seus contextos de ensino a partir da integração e da apropriação do uso pedagógico e funcional das (e com as) tecnologias digitais. 
De todo modo, a disciplina a respeito de tecnologias forneceu aos participantes do curso de Letras-Inglês oportunidades para refletir e usar pedagogicamente as tecnologias digitais para fins educacionais. Os alunos-professores confessam usar as tecnologias com frequência no dia a dia, mas não se sentiam preparados, confiantes, para usá-las como ferramentas educacionais. Acredito, assim, que essa disciplina curricular cumpriu seu papel acadêmico, inserida em um curso de graduação, com o propósito de conduzir os alunos-professores a refletir sobre como, por que, onde desejam chegar e em que nível as tecnologias podem ser usadas em seus contextos profissionais.

Após essas reflexões, sou levado a compreender que as tecnologias trazem múltiplas vantagens ao serem incorporadas à pedagogia da sala de aula de maneira reflexiva e crítica. Não há um manual pronto e definitivo sobre como usar as tecnologias para fins educacionais que se possa comprar em uma loja de departamento ou adquirir pela Internet, pois seu uso transcende o técnico e o instrumental. Faz-se necessário pensar as tecnologias como ferramentas integradoras e funcionais à formação dos alunos-professores nos cursos de licenciatura. Diante das reflexões colocadas, defendo, aqui, a necessidade, cada vez mais relevante, da formação tecnológico-digital e pedagógica do professor pré-serviço de inglês nos cursos de graduação, para torná-lo letrado digitalmente, considerando a expansão e o desenvolvimento das tecnologias no mundo atual.

\section{Referências}

Araújo, M. S. Tecnologias Digitais da Informação e Comunicação para Fins Educacionais na Formação Inicial de Professores de Inglês. 2017. 244 f. Tese (Doutorado em Linguística Aplicada e Estudos da Linguagem) - Pontifícia Universidade Católica de São Paulo (PUC-SP), São Paulo, 2017.

Bardin, I. (2011). Análise de conteúdo. Edições 70, São Paulo.

Kenski, V. M. (2013). Tecnologias e tempo docente. Papirus, Campinas.

Santiago, L. B. M.; NASCIMENTO, M. D. R.; Sampaio, R. M. L. O uso das tecnologias digitais na busca da superação do analfabetismo. In: V CONGRESSO BRASILEIRO DE INFORMÁTICA NA EDUCAÇÃO (CBIE), 2016, Uberlândia. Anais...Uberlândia: Universidade Federal de Uberlândia, 2016, p. 800-809.

Santos, L. M. A. Panorama das pesquisas sobre TDIC e formação de professores de língua inglesa em LA: um levantamento bibliográfico a partir da base de dissertações/teses da CAPES. Revista Brasileira de Linguística Aplicada, v. 13, n. 1, p. 15-36, 2013.

Savage, M. and Barnett, A. (2015). Digital literacy for primary teachers. Critical Publishing, Great Britain.

Stake, R. E. (1995). The art of case study research. SAGE Publications, London. 